\title{
Democracia deliberativa y movimientos juveniles contemporáneos
}

\section{Deliberative democracy and contemporary youth social movements}

\author{
Monserrat García Guerrero• \\ Carmen Fernández Galán Montemayor••
}

\begin{abstract}
Resumen
En este trabajo analizaremos los discursos de los movimientos juveniles en el estado de Zacatecas en el periodo 2012 a 2017 , donde distintos actores proponen una actuación democrática que se acerca a lo que Dryzek $(2000,2009)$ denomina democracia deliberativa. El objetivo es demostrar que los movimientos juveniles en Zacatecas transitaron ideológicamente de una postura asistencialista a una proactiva donde la participación ciudadana rebasa la esfera estudiantil y generacional. La metodología para determinar si en el periodo estudiado estos movimientos tuvieron una transición ideológica son las herramientas para el Análisis Crítico del Discurso (ACD) que proponeVan Dijk (1999) y la tipología de democracias de Osorio (20।4). La conclusión es que se da una transición en la esfera ideológica, no así en la acción política.
\end{abstract}

Palabras clave: movimientos sociales, juveniles, democracia, ideología.

\begin{abstract}
In this paper we analyze the discourses of youth social movements in the state of Zacatecasduring the period 2012-2017, where different actors propose a democratic behavior that approaches to what Dryzek (2000) calls deliberative democracy. The objective is to prove that youth social movements in Zacatecas had an ideological transit from a welfare position to a proactive one where citizen participation exceeds the student and generational sphere. The methodology used to determine if in the studied period this movements had an ideological transition are the Critic Discourse Analysis tools proposed by VanDijk (1999) and the typology of democracies by Osorio (2014). The conclusion is that there is a transition in the ideological domain but not in the political action one.
\end{abstract}

Keywords: social movements, youth, democracy, ideology.

\footnotetext{
- Maestra en Ciencias Sociales y Humanidades por la Universidad Nacional de Quilmes, Argentina y estudiante de Doctorado en Gestión Educativa y Política Pública de la Universidad Autónoma de Zacatecas. Es parte de la Red Internacional deMigración y Desarrollo, de la Federación Latinoamericana de Semiótica y de la Asociación Mexicana de Estudios del Discurso.—montsegarcia@uaz.edu.mx ORCID: 0000-0002-2303-0240

- Dra. en Humanidades y Arte por la Universidad Autónoma de Zacatecas. Docente investigadora en la Unidad Académica de Letras y Unidad Académica de Docencia Superior por la Universidad Autónoma de Zacatecas, Perfil Promep, SNI-C, Cuerpo académico UAZ- I70._carmenfgalan@gmail.com _ ORCID: 0000-0002-6926-6080

Fecha de recepción: 9 de octubre de 2019. Fecha de aceptación: 13 de octubre de 2020.
} 


\section{Introducción}

Los movimientos estudiantiles en México han sido un tema de debate continuo con marcados periodos de intensificación y donde se observan transformaciones en los roles y formas de participación de los jóvenes en la política nacional, por lo que en la actualidad se autodenominan movimientos "juveniles" en virtud de que rebasan la esfera universitaria. El discurso del joven que participa en movimientos sociales lo definen hoy como un protagonista clave de la historia reciente de la democracia mexicana.

La historia reciente de la movilización en México cuenta con experiencias como la de 1968 (Tlatelolco) y la de 1971 (el "halconazo") en el siglo pasado que siguen siendo referentes en el país. Estos movimientos estudiantiles o juveniles han tenido una notoria presencia en el ideario colectivo y siguen siendo parte del discurso contestatario; también existen otras experiencias que no han sido tan mediatizadas, quizá por las dimensiones de los dos movimientos mencionados. Pero existen otros elementos. La mayoría de los movimientos se focalizan en la capital, de ahí la importancia de rescatar lo que ocurre en otras regiones del país en ese sentido y además los movimientos estudiados en el presente texto se pueden entender como parte de un nuevo ciclo de movilización juvenil en México.

Los movimientos nacionales se orquestan con los movimientos regionales, tal es el caso de Zacatecas durante el ciclo de movilización iniciado en 2012. Los movimientos de continuidad y simultáneos al movimiento nacional YoSoy132 fueron: YoSoy132 Zacatecas (en adelante 132 Zac) y la Asamblea Popular Zacatecas (APZ), uno entendido como el inicio de la movilización juvenil contemporánea en la ciudad, y el otro como la maduración de este proceso.

Los discursos de estos movimientos en Zacatecas son analizados de manera comparativa para observar el tránsito 
de ideologías, que también es cronológico, puesto que un movimiento antecede al otro. El objetivo general del trabajo es dar lectura a las voces juveniles en movimientos sociales en Zacatecas desde el debate actual en torno a la toma de conciencia sobre los sistemas democráticos que existen en América Latina y específicamente en México.

Desde esta perspectiva y siguiendo la tipología de Osorio (2014), se toman los siguientes conceptos base: sociedad civil y democracia deliberativa, como opuesta a la democracia delegativa, procedimental y capitalista (Osorio, 2014). ${ }^{1} \mathrm{El}$ concepto de democracia deliberativa permite explicar el proceso que han seguido estos movimientos juveniles, ya que esboza otra idea de democracia dentro de sus propias filas. Este significado se acerca al discurso de los jóvenes, quienes piensan el movimiento social como una intervención en la democratización en México.

Se parte de la hipótesis de que los jóvenes pertenecientes a movimientos sociales en la ciudad de Zacatecas tuvieron un proceso ideológico que los ha hecho transitar de la visión dominante de democracia desde arriba, donde percibían la democracia y la política como prácticas negativas, hacia la idea de la democracia deliberativa, que implica el reconocimiento de los errores históricos y la búsqueda de nuevas bases teóricas en otras geografías, sobre todo en países latinoamericanos cuyas realidades se asemejan más a la mexicana, con visiones como la del buen vivir que se desar-

I. Osorio (2014) hace una tipología de la democracia que se vive en Latinoamérica: “a) La democracia procedimental.Aquélla impulsada por ciudadanos desinteresados que acuden cada tanto a votar, pero se mantienen alejados la mayor parte del tiempo. Entienden la política como el hecho de ir a votar.b) La democracia delegativa. Donde la persona electa siente que fue elegida para tomar las decisiones que considere más pertinentes, ostentando una legitimidad que se siente se obtuvo en las elecciones. c) La democracia capitalista. Una democracia al servicio del capital, donde se toman las decisiones por los intereses económicos de una pequeña parte de la población.Y cómo la respuesta a esta tipología se encuentra la democracia deliberativa propuesta por Dryzek $(2000,2009)$, que supone un proceso colectivo de toma de decisiones, mediante la continua participación de los ciudadanos". 
rollaron teórica y prácticamente en países como Bolivia y Ecuador (Acosta, 2013).

El análisis no sólo permite decir algo sobre el discurso de los movimientos juveniles zacatecanos de ese periodo, sino conocerlos por cómo intentan actuar en el contexto, y por cómo definen esa realidad. Se trata de un periodo de movilización caracterizado por un solo partido en el poder, por el repudio a la clase política, e identificado como el marco en el que se gestó un cambio político importante con la entrada al poder de Andrés Manuel López Obrador y Morena (Movimiento de Regeneración Nacional) con la promesa de un cambio de forma de hacer política en todo el territorio mexicano.

Entendemos el discurso de los jóvenes en movimientos sociales en Zacatecas como un discurso político, como un lugar privilegiado ya que el impacto de YoSoy132 a nivel nacional les permitió tener cobertura en la prensa, tener reconocimiento social y en resumidas cuentas les dio el marco bajo el que pudieron hacer visible su idea de mundo, y el rechazo que sentían ante la situación política en México, lo que derivó en que ellos se convirtieran en un actor político con fuerte presencia en la escena local y nacional.

Se utiliza el análisis crítico del discurso como opción para analizar un discurso emitido desde una posición privilegiada con el fin de que fuera recibido o consumido por un sector más amplio, que puede entenderse como las masas. Según la metodología de Van Dijk (2008, 2010), una lectura sistemática parte del "análisis del modo como los miembros de distintos grupos y organizaciones sociales que participan a través de distintas situaciones en la expresión (o no) y en la formulación del conocimiento mediante diversas formas de discurso público" (Van Dijk, 2010: 176); por esta razón el corpus discursivo que se analiza incluye textos proporcionados por los miembros, documentos y bitácoras resultado de 
las asambleas, videos realizados por los miembros y colgados en YouTube y entrevistas a miembros del movimiento. ${ }^{2}$

Esta metodología busca ser enriquecida al agregar elementos de otro tipo de análisis, como los estudios multimodales (Pardo y Forero, 2016) al analizar también el uso de máscaras y determinados medios de comunicación e información que permiten entender el discurso también desde una nueva realidad, pues los movimientos se están generando y desarrollando en una era digital (Raveli y van Leween, 2018), lo que cambia el contexto y la forma de lectura frente a experiencias de movilización anteriores.

\section{El discurso de YoSoy 132 Zacatecas}

Tanto a nivel local como nacional, para el año 2012 los debates sobre las bases del movimiento YoSoy132 se llevaban a cabo de forma continua, resaltando la discusión recurrente sobre si uno de los estandartes del movimiento debería de ser o no una confrontación directa contra Enrique Peña Nieto (entonces candidato presidencial) o si debería de ser una declaración contra el sistema político mexicano. YoSoy132 nacional realizó asambleas para tratar de ponerse

2. Video en YouTube. Enrique Peña Nieto en Zacatecas. Marcha anti-EPN, 27 de mayo 2012.

Video en YouTube. YoSoy I32, Marcha anti-EPN Zacatecas, 3 de junio de 2012.

Grabación proporcionada por los miembros. Declaratoria YoSoy 132, 6 de junio de 2012

Video en YouTube. Marcha NacionalYo Soy \#I 32 En Zacatecas Plaza Bicentenario, 10 de junio 2012.

Video en YouTube.Video hecho por el mismo movimiento donde ellos expresan las bases del movimiento \#YoSoyl32 en Zacatecas, 21 de junio de 2012.

Video en YouTube. Marcha y fiesta político-cultural contra la imposición y por la democracia, 22 de julio 2012.

Entrevistas con los miembros de YoSoyl 32 Zacatecas 2017.

Declaratoria de creación de Asamblea Popular Zacatecas 2016.

Presentación de APZ 2016.

Entrevista realizada por el director de La Jornada Zacatecas en el programa Sinergia, realizada el 7 de febrero de 2016.

Entrevistas personales realizadas a los miembros jóvenes de APZ 2017. 
de acuerdo en éste y muchos otros temas; las fuentes hablan de discusiones largas y de la búsqueda de consensos que nunca se consiguieron, pues las posturas de los diferentes oradores eran muy lejanas y nadie cedía.

El movimiento surgido en la "Ibero" derivó en distintas versiones en algunas entidades del país, destacando los casos de Nuevo León, Guanajuato, Jalisco y Zacatecas, o hasta en el extranjero, donde migrantes jóvenes se reunieron bajo esta denominación. ${ }^{3} \mathrm{Al}$ final cada versión del movimiento buscaba sus propias bases e identidad, mismas que englobaran su contexto y las necesidades locales que los miembros consideraron urgentes por defender o denunciar, tratando de ser fieles al mismo ideario.

La realidad es que no existen datos sobre si se llegó a un consenso nacional o internacional en este sentido, pero sí existen documentos y/o multimedia que buscan mostrar a la sociedad el estandarte bajo el cual se intentan legitimar como movimiento social. La narrativa de este movimiento como lenguaje es, en realidad, una forma de acción (Chilton y Schaffner, 2000: 299).

Las evidencias encontradas consisten mayormente en videos de movilizaciones realizadas por YoSoy132 Zacatecas, que muestran el recorrido por la ciudad de Zacatecas o eventos realizados en alguna plaza pública, donde destacan las consignas y las mantas impresas, así como los diferentes elementos gráficos (tales como pancartas, muñecos, camisas, máscaras). En varios videos se realizaron entrevistas donde los miembros del movimiento emiten discursos que se complementan con mensajes impresos y otros elementos gráficos.

El discurso emitido es una lucha por tambalear la representación social imperante que se tenía sobre la juventud o sobre los jóvenes en movimiento, representación moldeada

3. Tal es el caso de Reino Unido, Estados Unidos y algunos otros países. Se documentaron más de 40 en redes sociales.

\section{6}


por aquéllos en el poder, pues existe esta fuerte capacidad de construir subjetividades; el uso de sistemas de codificación e interpretación específicos muestran las tendencias políticas de los grupos determinados, así las culturas juveniles actúan como expresiones que codifican a través de símbolos y lenguajes diversos la esperanza y el miedo (Reguillo, 2012: 15).

La narrativa dominante sobre participación política y juventud marcaba varias categorías a las que se contrapusieron los propios jóvenes. Estas categorías son: a) jóvenes poco comprometidos, que son aquellos que no muestran interés por la realidad que los rodea; b) jóvenes interesados o "calculadores", que son quienes ingresan a los movimientos sociales para buscar entrar a otras esferas como la de los partidos políticos; c) jóvenes inocentes, que están en movimientos sociales sin conocer realmente los ideales que persiguen, y d) jóvenes "irracionales" que realizan vandalismo o que se exponen y provocan violencia. ${ }^{4}$

El discurso oficial trataba de deslegitimar a los jóvenes del movimiento 132 dando otro tipo de información a la sociedad, esperando ocasionar un impacto en las urnas. El 1 de julio de 2012 podría verse como el día de la derrota del YoSoy132, como la fecha en que todos sus esfuerzos se vieron empañados con la victoria de Enrique Peña Nieto, el mismo que había sido criticado y enjuiciado por meses.

Con la necesidad de los jóvenes de mostrar todo lo que estaba mal, en el discurso hay dos actores contrastantes, antagonismo marcado que permitiera ver a los gobernantes con todas las características negativas y a ellos mismos con las positivas. A continuación se enumeran los principales actores que aparecen en el discurso de YoSoy132 Zacatecas, entendidos en una dinámica de nosotros y los otros, en un esfuerzo de mostrar dualidades entre lo que consideraban

4. Categorización de elaboración propia con base en la información de medios y oficial encontrada sobre el movimiento YoSoyl 32 en el periodo 2012-2016. 
correcto y lo que no. Resalta que en la categoría de los otros nunca se les da el papel de interlocutores o voceros, sino que funcionan como figuras a criticar, como representaciones de todo lo que se considera malo dentro de la política mexicana.

\section{Tabla 1}

Actores del discurso YoSoy132 Zac

\begin{tabular}{|c|c|c|c|}
\hline \multicolumn{2}{|l|}{ Los otros } & \multicolumn{2}{|l|}{ Nosotros } \\
\hline Enrique Peña & Político. & Jóvenes & Apolíticos. \\
\hline Nieto & No lee. & & Leen. \\
\hline $\begin{array}{l}\text { Carlos Salinas } \\
\text { de Gortari }\end{array}$ & $\begin{array}{l}\text { Corrupto. } \\
\text { Titiritero. }\end{array}$ & Estudiantes & $\begin{array}{l}\text { Ideales loables. } \\
\text { No movidos por } \\
\text { nadie. }\end{array}$ \\
\hline $\begin{array}{l}\text { Partido } \\
\text { Revolucionario }\end{array}$ & $\begin{array}{l}\text { Partido en el } \\
\text { poder. }\end{array}$ & Anonimous & $\begin{array}{l}\text { Verdad. } \\
\text { Investigación. }\end{array}$ \\
\hline $\begin{array}{l}\text { Institucional } \\
\text { (PRI) }\end{array}$ & Fraude. & & Información. \\
\hline $\begin{array}{l}\text { Medios de } \\
\text { comunicación } \\
\text { tradicionales (tv, } \\
\text { radio, prensa) }\end{array}$ & $\begin{array}{l}\text { Tergiversan } \\
\text { información. } \\
\text { Se venden. }\end{array}$ & $\begin{array}{l}\text { Medios } \\
\text { alternativos }\end{array}$ & $\begin{array}{l}\text { Hablan de la } \\
\text { realidad. } \\
\text { No se venden. }\end{array}$ \\
\hline Miguel Alonso & Corrupción. & YoSoy132 & Alternativa. \\
\hline Reyes & $\begin{array}{l}\text { Nepotismo. } \\
\text { Clientelismo. }\end{array}$ & Zacatecas & $\begin{array}{l}\text { Lucha. } \\
\text { Verdad. }\end{array}$ \\
\hline
\end{tabular}

Fuente: elaboración propia a partir del corpus.

En el cuadro queda ilustrado que los otros siempre tienen nombre, apellido y filiación partidista, se trata de gobernantes de los diferentes niveles como sucede con Peña Nieto y Miguel Alonso, entonces presidente de la República y gobernador del estado de Zacatecas, respectivamente, y con Carlos Salinas de Gortari, una figura criticada por años como el causante de las crisis mexicanas y señalado como la mente detrás de muchas decisiones gubernamentales; en este mismo tenor se habla del Partido Revolucionario Institucional (PRI) como representación de la podredumbre 
del sistema partidista y de Televisa como medio de información corrompido.

Justo en el otro extremo encontramos la idea de comunidad, usando referencias a los jóvenes como una unidad integrada, los estudiantes, la referencia a Anonimous y a medios alternativos contra periodistas "vendidos" y la referencia a su propio movimiento, todos estos nosotros como una fuerza integrada, contrario a los intereses personales y clientelares de los otros.

Los discursos hacen una diferencia al hablar de lo propio, el nosotros, y del otro. Por un lado, en lo propio están las características personales de los miembros, en tanto para hablar del YoSoy132 se acude a argumentos más universales; de esta forma se refieren a ellos mismos como estudiantes, jóvenes, gente informada y "no manipulada", todos, nosotros, y figuras como Anonimous a modo de representación de "la verdad", pues esa máscara puede esconder o invisibilizar variadas identidades. La figura de Anonimous aparece en todos los videos analizados donde jóvenes usan la máscara característica de este grupo que desde hace años se manifiesta en favor de la libertad de expresión, menos en el de presentación del movimiento 132 Zac en junio de 2012.

La contraposición se deja ver en cuanto a la descripción de grupos grandes para el primer caso y acusados específicos para el segundo. Esta distinción en el lenguaje es uno de los elementos que deja visibles las demandas, también en las pancartas donde se visualiza a los personajes a quienes se les quiere adjudicar la culpa de la situación contra la que los 132 Zac está inconforme. Así encontramos múltiples referencias al "copetón" que no lee y por tanto no tiene conocimientos, y se compara con el joven estudiante que lee y por tanto, siguiendo su propia premisa, está informado, lo que los posiciona en una situación privilegiada para juzgar a aquellos que no cuentan con el bagaje académico/cultural. 
Esta idea del joven, del estudiante, del luchador, tiene reminiscencias a una idea romántica y rebelde, para mostrarse a sí mismos como diferentes, como aquellos que buscan el cambio, que pueden hacer la diferencia contra las personas específicas que tienen sumido al país en reiteradas crisis y abusos. Al final este recurso se torna en una visión maniqueísta del mundo: los buenos contra los malos, los corruptos contra los que buscan la democracia, los informados contra los no informados, los que leen contra los que no lo hacen. Tales estrategias discursivas tuvieron su contraparte, pues tocaron a un sector de la sociedad que se sintió ofendido al escuchar este tipo de discursos.

El propósito de 132 Zac era demostrar a la sociedad la realidad de la clase política, o más bien de un sector específico de esta clase política, y la corruptela en el Gobierno mexicano. Frente a esto la opción parecía la información, la lectura, el conocimiento, pero no se tomó en cuenta que un amplio sector de la población mexicana no tiene prácticas de lectura y que al ofender a los gobernantes por el poco conocimiento, también estaban ofendiendo a otros; en este sentido los YoSoy132 se vieron como un grupo altanero, que se creía poseedor de la verdad, que se vanagloriaba de ser muy ilustrado, que estaba en contra de todo, y que a final de cuentas no logró hacerse escuchar por el grueso de la sociedad, pero que a pesar de eso, sí pudo entrar en esferas donde antes los jóvenes no tenían injerencia.

Si bien los miembros de 132 Zac no mostraron un asidero teórico explícito como otros movimientos, en los discursos sí es posible encontrar numerosos rasgos de una ideología marxista, al estudiar el contexto se constata que estos jóvenes son los hijos de aquellos estudiantes zacatecanos que se movilizaron en los setenta. De ahí se heredan las analogías: los trabajadores, esto era los proletariados, las cúpulas del poder (o los burgueses) y sobre todo la necesidad de contraponer dos mundos, el del capital y los que le sirven, 
los explotados; en síntesis, la lucha de clases. Aunque en ningún momento 132 Zac se reconoce como marxista, existe esa ideología implícita, ya que en el discurso hay un llamado a la acción, una convocatoria dirigida al proletariado para que se levante contra el orden burgués o su equivalente actual, el orden del capital.

Dentro del tópico de la luchas de clases se da importancia a ciertos acontecimientos de la historia reciente del país, para validar el argumento de la necesidad de luchar contra el sistema actual, contra el Gobierno y el partido en el poder. Los sucesos o hechos a que se recurre en el discurso son: a) la matanza de Atenco; b) la "casa blanca" de la primera dama; c) el fraude electoral y la compra de votos; d) el episodio en la FIL de Guadalajara.

Todos estos sucesos son los que originan las diferentes consignas y discursos de 132 Zac, resaltando que todos ellos involucran a EPN. Aunque parecía que no había consenso sobre si el movimiento debería o no ser contra EPN, los elementos de los discursos demuestran que daba muchos elementos para la realización de crítica y la sátira, en este sentido, resalta el trabajo de Gutiérrez y Cuevas (2012) sobre las representaciones sociales de EPN en el periodo en que tuvo mayor auge el movimiento 132.

Las jóvenes del movimiento 132 Zac presentaron siempre a un EPN digno de mofa, poco serio, y con poca capacidad intelectual, por tanto no era digno de ostentar el puesto de presidente de la nación. A veces las burlas pasaron a ser ofensas claras, pues las consignas de los eventos subían de tono; sin embargo ellos estaban totalmente convencidos de que tenían la razón y de que tenían la obligación moral de dar a conocer estas verdades.

Los acontecimientos mencionados anteriormente se entendían como vox populi, pues la prensa y sobre todo las redes sociales les habían dado cobertura, y eran eventos conocidos por la población mexicana, de ahí nacieron varias 
frases del movimiento 132 Zac: "El pueblo informado jamás será acarreado" (mientras pasaba la gente que iba a recibir a Peña Nieto) (Visita EPN, 2012), "Mi voto no se vende", "Hay que leer, hay que leer, si no un pendejo como Peña vas a ser", "Mis sueños no caben en una pantalla", "EPN la prole te saluda", "Atenco no se olvida", "Tienes tus manos manchadas de sangre EPN".

Todas las consignas daban cuenta de un saber común, información generalizada que había llegado a la población sobre los excesos de EPN y sus desaciertos fueron los principales motores de los discursos, dejando claro lo señalado por Luhmann:

El gran acervo de conocimientos de lo que sabemos y creemos sobre el mundo no proviene de nuestra experiencia directa de él, sino de los medios de difusión. De tal suerte, la manera en que éstos seleccionan cierto contenido informativo y definen la forma de difundirlo influye, sin duda, en la construcción de la realidad mediática y, por tanto, en cómo ésta es interpretada y significada (Luhmann, 2000, citado en Estrada, 2014: 118).

Otros recursos de 132 Zac fueron textos de otra índole donde recuperaron frases poéticas, reflexiones de Benedetti y de Ernesto Che Guevara, así como de otros escritores, donde destacan pensadores mexicanos como Jesús Silva Herzog y Paco Ignacio Taibo II. Los integrantes realizaban círculos de estudio, muchas veces abiertos y realizados en plazas públicas. En estos círculos de estudio destacan los autores u obras que se detallan en el siguiente cuadro. 
Tabla 2

Textos referenciados en discurso de YoSoy132 Zac

\begin{tabular}{|c|c|c|c|c|}
\hline Teoría & Historia & Literatura & Poesía & $\begin{array}{l}\text { Video/ } \\
\text { pelicula }\end{array}$ \\
\hline Etienne de & Eduardo & George Orwell & Ernesto & Brazil. Terry \\
\hline La Boite & Galeano & & Cardenal & Gilliam. \\
\hline Slavoj & Mario & Ray Bradbury & César & El club de la \\
\hline Zizek & Benedetti & & Vallejo & $\begin{array}{l}\text { pelea. David } \\
\text { Fincher. }\end{array}$ \\
\hline Mijail & Paco Ignacio & Jorge & Miguel & La doctrina \\
\hline Bakunin & Taibo II & Ibargüengoitia & Hernández & del shock. \\
\hline Noam & Rogelio & Alan Moore & Eduardo & ¡Zizek!. \\
\hline Chomsky & Vizcaíno & & Lizalde & SlavojZizek. \\
\hline Camile de & Álvaro & Antonio & Nicolás & La lengua de \\
\hline \multirow[t]{13}{*}{ Toledo } & Delgado & Tabucci & Guillén & las mariposas. \\
\hline & Carlos & Ricardo Piglia & Juan & "La última \\
\hline & Fuentes & & Geldman & salida a \\
\hline & & & & Springfield". \\
\hline & & & & Los Simpson. \\
\hline & & & León Felipe & Capitalismo: \\
\hline & & & & Una historia \\
\hline & & & & de amor. \\
\hline & & & & Michael \\
\hline & & & & Moore. \\
\hline & & & Manuel & Underground. \\
\hline & & & Maples Arce & Emir \\
\hline & & & & Kusturica. \\
\hline
\end{tabular}

Datos del círculo de lectura proporcionados por Eduardo Goitia, líderes de YoSoy132 Zacatecas.

El movimiento YoSoy 132 Zacatecas siguió trabajando como colectivo y sus actividades se pueden rastrear todavía a finales del año 2014, y fue en el periodo de finales de 2012 hasta su disolución que se vio cómo diferentes integrantes de esta iniciativa se fueron separando, de ahí que para el año 2015 pareciera que esa movilización juvenil y cualquier otra habían desaparecido por completo del mapa zacate- 
cano. Podría creerse que la experiencia organizativa había sido negativa y que los impactos fueron devastadores; pues muchos de los miembros se alinearon a partidos políticos y otros tantos buscaron alternativas fuera de la entidad, resultando en que la presencia juvenil organizada que se mantuvo por lo menos durante dos años como una constante, ya no se presentara en las calles.

Muchos de los miembros más comprometidos de YoSoy 132 Zacatecas se integraron al trabajo de partidos políticos autoproclamados como de izquierda, y para aquellos que se resistieron a eso las opciones se volcaron al estudio, a la búsqueda de ofertas laborales y en el caso específico de dos de sus miembros, iniciativas que permitieran la subsistencia, pero que no se alejaran de sus ideales:

[...] unos se van por ciertos partidos, o continúan en la universidad y algunos de nosotros tenemos tendencias más [...] algunos comunistas y otros libertarias, cuestiones hasta cierto punto teóricas, pero que en la práctica nos llevan a un actor distinto, necesariamente [...] (Francisco González, Sinergia, 7 de febrero de 2016).

Del 132 Zac parten varias vertientes, como colectivos feministas, anarquistas, frente de estudiantes universitarios (FEU) y Asamblea Popular Zacatecas (en adelante APZ), muchos de ellos seguían subsistiendo al año 2020, fecha en que se escribe este trabajo.

\section{El colectivo Asamblea Popular Zacatecas}

En lo que sus miembros fundadores consideran un momento de maduración, nace APZ. Resultado de la iniciativa de 132 Zac y las lecciones aprendidas, no sólo política sino personalmente en la experiencia de desencanto y separaciones, y variados aprendizajes como el enfrentamiento con fuerzas públicas (policiacas), la conciencia de 
que muchos de sus discursos resultaban ofensivos para buena parte de la sociedad, los problemas al interior de la movilización, los infiltrados y las amenazas u ofrecimientos del poder oficial.

Luego de la experiencia de 2012, los integrantes de 132 Zac reorientaron su rumbo de manera individual, algunos se integraron a iniciativas como la zapatista, la comunista, otros a partidos políticos, y unos más simplemente se retiraron de la política. La reagrupación como APZ se asumió como:

[...] una organización social, es una iniciativa en construcción, no somos la esperanza, ni somos algo ya creado, somos algo en construcción, en continuo aprendizaje, con ganas de corregirse y cometer errores obviamente [...] (Entrevista Eduardo Goitia, Sinergia, 7 de febrero de 2016).

El 31 de enero de 2016 se produjeron los primeros indicios rastreables de lo que sería la APZ, para que en esta fecha se pudiera dar una declaración como movimiento se había hecho un cabildeo de varios meses con diferentes organizaciones sociales e individuos. Antes de que se hablara de la iniciativa, los precursores (Eduardo Goitia, Francisco González y Emilia Pesci, principalmente) sostuvieron pláticas con representantes, líderes e integrantes de numerosas organizaciones, de forma que se pudieran conocer e integrar las inquietudes, luchas, ideales y bases de todos ellos.

La propuesta se abrió junto con una página de Facebook y se convocó a rueda de prensa para presentar a la Asamblea Popular Zacatecas como colectivo de colectivos, que retoma su nombre de la experiencia de la Asamblea Popular de los Pueblos fundada en Oaxaca en 2006. A partir de enero de 2016 se pueden encontrar diferentes discursos emitidos por los miembros de APZ donde se reconocen los principales temas de interés, y la influencia de movimientos y luchas a nivel nacional: a) Rompimiento con el Estado, lo que significa entender política como participación social, no 
como el trabajo para fines electorales, se buscan procesos organizativos horizontales. b) Propuestas anticorrupción. Integración de un frente común amplio, juntar las diferentes voces para hacer más fuerte cada iniciativa. c) Búsqueda de una organización más abarcadora con base en el reconocimiento de encuentros y diferencias.

Sobre el rompimiento con el Estado, destaca en el discurso la idea de poder hacer cosas de forma paralela al Estado, se habla de una conciencia social, de un hacer política desde abajo, ya no como exigencia a los de arriba, para volverse dueños de la propia realidad:

Necesitamos dejar de ver las necesidades como exigencias a las instituciones, porque no queremos salud, queremos sanar, y reapropiarnos de lo que es el buen vivir, ¿no? El Estado en ese sentido no va a poder hacer nada, y no sería correcto que lo hiciera, desde mi punto de vista, porque la sociedad tenemos que madurar como eso (Francisco Goitia, Sinergia, 7 de febrero de 2016).

El discurso se enfoca ahora en el actor social, ya no tanto en el otro contra quien hay que luchar, se trata de una invitación a una conciencia diferente, menos asistencialista, que busca que las personas se empoderen y sean capaces de reconocer que pueden tener injerencia en la vida política y social de su país y de sus estados. La palabra política no se usa con tintes negativos, sino como una posibilidad de entenderla y vivirla desde otra arista, de apropiarse de los espacios de participación. Lo que parece que sucede en los diferentes discursos analizados es que los jóvenes han decidido poner un ejemplo a la sociedad de cómo vivir la política de forma diferente, el asunto es invitar a participar participando.

En la cita resalta el conocimiento del debate académico y social sobre el "buen vivir", que desde hace algunos años ha adquirido protagonismo en los discursos académicos y 
políticos latinoamericanos. El "buen vivir" se enfoca en las personas y el respeto de su entorno como alternativa al desarrollo, sobre todo a las políticas capitalistas. Desde esta perspectiva, la maduración social implica entender que cada quien tiene en sus manos su realidad, que ya no se pueden esperar las respuestas desde arriba, pero que también se tiene la capacidad de rechazar las decisiones tomadas por aquéllos en los puestos gubernamentales. Si bien no es un rechazo pleno al Estado, se quiere desmitificar al político mexicano como aquella persona que puede tomar decisiones sobre la realidad común, y volver a ponerlo como una persona al servicio de la sociedad, alguien que puede ser increpado, aconsejado y vigilado por la comunidad.

Sobre las propuestas anticorrupción se hizo un trabajo entre las organizaciones, labor que terminó en una numeralia de elementos para incidir en la vida política, porque el tema de la corrupción o la lucha contra esta práctica fue el punto de coincidencia, de esta forma encontramos en el planteamiento de APZ las siguientes medidas:

1. La creación de un tribunal de rendición de cuentas.

2. El impulso para la separación de la Procuraduría de Justicia.

3. Un tabulador de sueldos y salarios, para los puestos gubernamentales.

4. La promoción de una ley de participación ciudadana.

5. La autonomía del Poder Judicial en el nombramiento de magistrados.

Con la finalidad de ofrecer propuestas de acción contra los elementos que dañan la democracia y la vida pública del país, en esta nueva propuesta de movilización se desarrollaron propuestas para presentar a los legisladores como una forma de reconocer su papel como ciudadanos activos de la vida pública y política del país. 
En los cinco puntos anotados se reconoce que se trata de propuestas que podrían ser retomadas por cualquier partido político como elementos de convencimiento, con la diferencia de que ahora se intenta que la gente conozca y se adueñe de las implicaciones de estos cambios. En este discurso hay una idea de democracia que ve a la corrupción como un impedimento para la toma de decisiones, como lo expresa el fragmento que se plasma a continuación:

Mucho hemos hablado ya del mal gobierno, de la corrupción, del nepotismo, del despotismo, de lo mal que hacen el actuar público y el ejercicio de los recursos las y los políticos que manejan la administración de nuestro país y nuestro estado; bastante hemos gritado consignas, hecho marchas, divulgado panfletos, pedido audiencias con autoridades, presentado propuestas a instituciones, tocado de puerta en puerta para hablar sobre lo mal que anda este país y lo mejor que podemos lograr organizados (Carta de presentación de la APZ, 2016).

Para lograr una organización más abarcadora y la integración de muchas y diferentes voces, APZ se vio en la necesidad de trabajar en propuestas que no tuvieran veto para ningún tipo de persona, pues en movimientos anteriores la gente podría sentirse impedida por motivos etarios, de condición económica, de sexo u otros. Tal integración no busca empatar a los sujetos, y se entiende que no es posible estar de acuerdo en todo, sino que se realza la necesidad de unión para tener impacto y poder converger en luchas.

Todos los colectivos que integran APZ representan una preocupación que se puede resumir en temas clave: extractivismo, feminismo, rendición de cuentas, defensa de los espacios públicos, pero que no se limitan a estos temas, ya que están abiertos a otro tipo de iniciativas, lo que hace que su discurso sea menos imperativo, manifiesto en el uso de verbos de posibilidad y no tanto fácticos, que indican que no se asumen dueños de la verdad. Como colectivo de 
colectivos los grupos e iniciativas fueron varios, donde se mezclan sus miembros, cambian de nombre, incluyen otras preocupaciones o luchas, con la constante de la permanencia de los temas locales, como los movimientos Salaverna Resiste, Aquelarre, Sociedad Civil en Defensa del Mercado González Ortega, Braceros, Cabildo Ciudadano, entre otros, que surgieron en el estado de Zacatecas entre los años 2015 y 2018.

El uso de frases célebres o fragmentos de pensamiento de gente reconocida nacional e internacionalmente es una práctica recurrente para APZ; en las entrevistas realizadas a ellos, así como en los discursos emitidos se encuentra información que nos lleva a reconocer a las personas que siguen, leen y con quienes comparten ideología, dejando así los mensajes respaldados por quienes ellos consideran autoridad; en este sentido encontramos referencias a académicos, escritores, pensadores y personajes ilustres conocidos por manejar tendencias anarquistas, estudios para el desarrollo o de defensa del pueblo. De esta forma, se encuentran tres categorías bajo las que se pueden enmarcar las referencias en los discursos de APZ.

Tabla 3

Temas de referencias discurso $A P Z$

\begin{tabular}{lll}
$\begin{array}{l}\text { Anarquistas } \\
\text { Enrico Malatesta }\end{array}$ & Defensa del pueblo & Académicos/escritores \\
Élisée Reclus & José Martí & Raúl Zibechi \\
Rudolf Rocker & Emesto Che Guevara & Octavio Paz \\
$\begin{array}{l}\text { Piotr Kropotkin } \\
\text { Murray Bookchin }\end{array}$ & & Edgardo Buscaglia \\
(ecologista) & & John Ackerman \\
\hline
\end{tabular}

Fuente: elaboración propia con datos de los discursos analizados. 
Cabe resaltar que no hay referencias marxistas en estos discursos, aunque sí se explicita una conciencia de la posición social e ideológica. Por ejemplo, en la Genealogía de la revuelta de Zibechi (2003), que en el milenio ha sido un referente sobre movimientos sociales que ayudó a APZ a la toma de conciencia sobre su rol social. El libro de Zibechi (de la única referencia que se hace en el documento de presentación de la APZ) recupera los logros de las luchas sociales recientes, no sólo en Argentina sino en todo el mundo.

Raúl Zibechi comentaba que no hay que desgastarnos en convencer a todos y a todas de la explotación y de lo mal que anda el mundo, más bien hay que encontrar a quienes tampoco les parece bien cómo se vive en nuestro entorno $y$, organizados o no, generar al menos el diálogo plural de lo que no vemos bien y de lo que podemos y queremos mejorar, sin prejuzgar a nadie desde ninguna ideología política, idiosincrasia o creencia religiosa; el escritor dijo también que el capitalismo y la explotación no se crearon de un día a otro con gente gritando "viva el capitalismo", sino que se fue generando por acciones concretas y cotidianas de los seres humanos; por lo tanto, para terminar con él hay que hacer lo mismo pero a la inversa (Presentación APZ, 31 de enero de 2016).

Zibechi es la fuente más presente en todo el discurso, hecho que muestra el acercamiento a la literatura sobre movimientos sociales. En ese mismo tenor se hacen referencias a Buscaglia y Ackerman, sobre todo en sus publicaciones sobre las candidaturas independientes, tema que toca a la APZ de forma directa con la experiencia de Cabildo Ciudadano. Estos académicos/escritores son referenciados en forma de ideas completas, no son sólo fragmentos o frases célebres sino que se problematizan sus tesis y se hacen referencias a las discusiones de sus textos.

Por otro lado, las referencias a los anarquistas se encuentran siempre como cita textual, extractos elegidos, o quizá 
compartidos de otras redes, que buscan reafirmar las ideas que se quieren promover: tomar el destino en las propias manos, crear medios propios de producción, salir de la oleada capitalista, ir contra el neoliberalismo y la explotación, como en Malatesta, Reclus, Rocker y Kropotkin.

Para el caso de las referencias catalogadas como defensa del pueblo, sobresalen frases célebres y lugares comunes que APZ utiliza para expresar una forma de actuar, o una ideología. No es casualidad que aparezcan personajes como Emiliano Zapata, el Che Guevara o José Martí, porque cuando se habla de ellos no importa tanto lo que se diga sino lo que viene implícito en su imagen que viene a la mente de quien escucha o lee. Se evocan de este modo figuras reconocidas porque lucharon por el bien común, beneficiaron al pueblo. He aquí algunos ejemplos de las frases empleadas en movilizaciones de APZ: "Los derechos se toman, no se piden, no se arrancan, no se mendigan”, de José Martí; "Sepan los nacidos y los que van a nacer, que nacimos para vencer y no para ser vencidos", de Ernesto Che Guevara; y "Si no hay justicia para el pueblo, que no haya paz para el gobierno", de Emiliano Zapata.

Estas tres frases hablan de lucha, de seguir en pie, y de una amenaza; aunque pareciera una contradicción con el discurso que se maneja de ya no culpar al otro, sino tomar las riendas y hacerse responsable. Las citas deben entenderse en este sentido, no son una amenaza contra nadie, sino un dejar saber que en adelante las riendas se están tomando y se están despertando conciencias.

En el momento del conflicto, muchas de estas transformaciones pueden parecer pequeñas e insignificantes, pero, cuando son tomadas en conjunto como parte del movimiento, es maravilloso ver cuánta tierra ha viajado en la creación de nuevas formas de lucha, formas que dan esperanza, formas que abren nuevas perspectivas (Holloway, 2002: 2). 
Quizá la referencia que pudiera englobar o resumir los ideales y búsquedas de APZ es Murray Bookchin et al., a quienes atribuyen el municipalismo libertario. La utopía es posible (2004) es una compilación de textos de Murray Bookchin, Domenico Liguri y Horst Stowasser; APZ cita un fragmento del capítulo de Stowasser "Proyecto A" que se escribe como instrumento de selección para la creación de un colectivo de gente que toma sus propias decisiones. "Proyecto A" describe un plan detallado para crear una comunidad con gente que quiera vivir separada del Estado, gente con ideas anarquistas, libertarias, que quiera instalarse y vivir en comunidad con otras personas que ostenten estos mismos ideales, creando lo que Stowasser llama "una isla anarquista" en Alemania, que después pudiera influir en todo el país y quizá después traspasar fronteras. De esta obra se toman gran parte de los contenidos de los discursos de APZ:

Nosotros preferimos vencer al Estado primero en las conciencias y luego en las realidades sociales y mediante la actuación ofensiva, subversiva y directa de la gente. Queremos que la gente se desvincule de toda lealtad al Estado, tomando su destino en sus propias manos (Documento de presentación APZ, 2016).

Aunque APZ no expresa abiertamente ideas anarquistas en los discursos, se encuentran muchas similitudes con esa ideología: a) el libre acuerdo; b) respeto a las diferencias; c) no hay un líder, se toman decisiones en asamblea; c) se integra a personas que ya hayan sufrido derrotas; d) convertir a los hombres en buenos feministas, entre otras. La APZ quiere implementar la idea de que "La política verdadera es la gestión de una comunidad por la gente de la misma comunidad por asambleas" (Bookchin et al., 2004: 76).

Al final las similitudes entre el Proyecto A y la APZ pueden ser resumidas en que ambos son iniciativas para un cambio en la sociedad actual, transformar paradigmas y formas de 
vivir la política. Mientras la propuesta de Stowasser busca modelos de autogestión, la APZ busca modelos de preparación de entes políticos, los dos con el objetivo de debilitar los aparatos del Estado y las instituciones, a lo que se suma la idea del "buen vivir" del proyecto alemán. En el municipalismo libertario las instituciones creadas de democracia directa estarían formadas por asambleas de ciudadanos, reuniones generales en las que todos los ciudadanos de un área determinada se reúnen, deliberan y toman decisiones.

En los medios informativos compartidos en las redes sociales de APZ hay otros referentes más actuales, diferentes a los ya mencionados académicos e ideológicos. En este sentido encontramos cuatro categorías: medios informativos formales, medios informativos alternativos, redes sociales de organizaciones y redes sociales de organizaciones miembros de APZ.

\section{Tabla 4}

Medios informativos usados en discurso de APZ

\begin{tabular}{|c|c|c|c|}
\hline Medios & Medios & Redes sociales de & Redes sociales \\
\hline informativos & informativos & organizaciones & de miembros \\
\hline tradicionales & alternativos & & $A P Z$ \\
\hline La Jornada & Contralínea & Mexicali Resiste & Aquelarre \\
\hline & & & Zacatecas \\
\hline El Universal & Oaxaca.media & Grupo Acción & Salaverna \\
\hline & & Revolucionaria & Resiste \\
\hline Univisión & Portaloaca.com & Periódico Acracia & Asamblea \\
\hline & & & Estatal de \\
\hline & & & Resistencias \\
\hline & & & Ciudadanas \\
\hline & & & Zacatecas \\
\hline El Sol de & Radio Zapote & & Cabildo \\
\hline Zacatecas & & & Ciudadano \\
\hline Revista Proceso & Guerrilla & Cruz Negra & Nosotrxs \\
\hline & comunicacional & Anarquista & \\
\hline & México & México & \\
\hline
\end{tabular}

Sociedad No.8I 


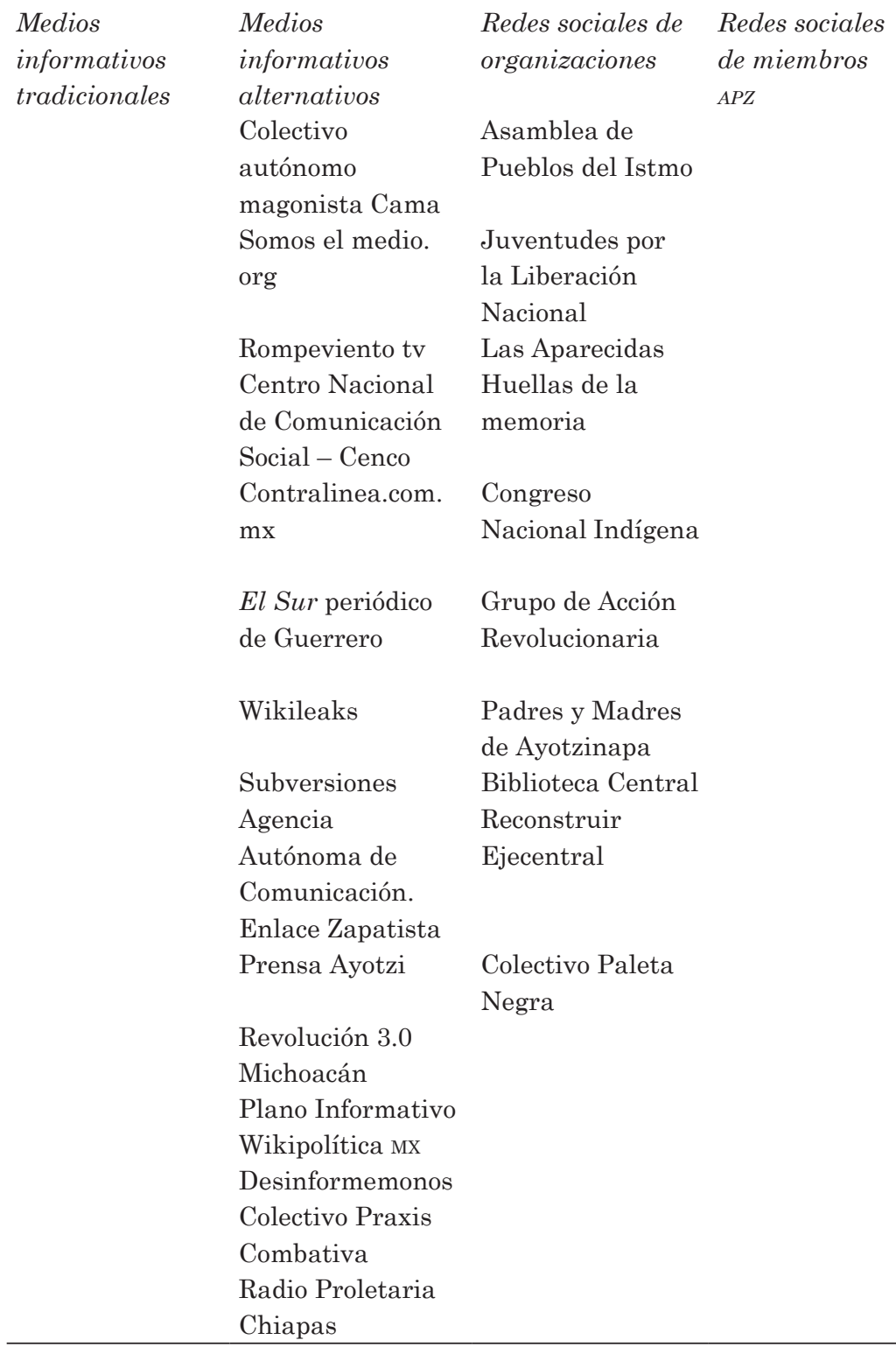

Fuente: elaboración propia a partir del corpus. 
Los medios informativos tradicionales son fuentes de información constituidos bajo las bases del Estado; para esta categoría resalta que su información es usada cuando se exponen eventos específicos, como es el caso de notas de los periódicos Reforma y El Universal que son reconocidos por ser medios de comunicación alineados al poder, o para el caso de Univisión, que es un canal de televisión de habla hispana en Estados Unidos. Con la revista Proceso y el diario La Jornada es diferente, pues estos medios son reconocidos por publicar notas contra aquéllos en el poder y por estar más en contra del partido político dominante en el país.

La segunda categoría es la más nutrida en cuanto a número de fuentes encontradas, y aquí resaltan opciones informativas del sur de México, principalmente de Chiapas, Oaxaca, Guerrero y Michoacán, que son estados reconocidos por sus actividades guerrilleras, zapatistas, combativas y de lucha contra el orden del Estado. En entrevista con Eduardo Goitia, líder de APZ, comenta la necesidad de en vez de luchar contra los medios tradicionales, tratar de convertirse en medio, usando las potencialidades que las nuevas tecnologías permiten explotar, por ello usaron las redes sociales como herramienta de coerción y divulgación de eventos, opiniones e ideas.

En el tercer grupo, el de redes sociales de organizaciones se sigue un patrón parecido al anterior, los grupos que seguidos son aquéllos del sur: asociaciones como Ayotzinapa, Asamblea del Itsmo, Congreso Nacional Indígena, entre otros grupos que publican sus actividades y denuncias de lo que consideran faltas contra sus derechos; destacan el grupo Cruz Negra Anarquista de México, cuyos ideales se acercan a Bookchin. Y un grupo del norte del país llamado Mexicali Resiste. Lo que demuestra que poco a poco los diferentes estados del centro y del norte se han ido sumando y no sólo son los estados del sur de México, tradicionalmente reconocidos por su historia de luchas sociales y subleva- 
ciones, los que realizan acciones en contra de decisiones gubernamentales que afectan su bienestar.

En las redes sociales de miembros de APZ el léxico tiene un tono menos subversivo, ya que evitan palabras ofensivas o ataques directos; en vez de referirse a personas corruptas, utilizan el concepto de corrupción, en vez de criticar a los partidos políticos se habla de tendencias, reconociendo con esto que en la política no deben ser parte sólo los partidos políticos, sino toda la sociedad, preferiblemente organizada, para así poder tener resultados positivos.

$Y$ en ese mundo que deseamos no existen diferencias de colores o partidos, existen diferencias de opiniones de hombres y mujeres libres; no existen los gobiernos opresores ni los explotadores, existe gente con ánimos de servir a su comunidad y las propuestas colectivas para el bien común (entrevista Francisco González, 2016).

Como lo señala el párrafo anterior, ya no se habla de gobiernos específicos que están fallando, se presta atención a las posibilidades, el discurso se enfoca en el quehacer, la crítica viene al ciudadano y ya no al gobernante, se encuentran palabras como resonancia y soluciones, se da poco espacio a la crítica y la confrontación. Las palabras están planteadas de forma propositiva en lugar de agresiva, la organización no es una amenaza sino una alternativa política.

\section{Conclusiones}

Los jóvenes miembros de movimientos sociales en Zacatecas, México, cuyos discursos se estudian en este trabajo han participado de la vida política del estado desde el año $2012^{5}$ a la fecha, periodo en el que han encontrado eco de sus acciones a través de diferentes formas, como el hecho

5. La historia de los movimientos estudiantiles en Zacatecas comenzó en la década de los setenta en el marco del conflicto universitario de 1977.

\section{6}


de incursionar en la vida electoral de la ciudad de Zacatecas, ser recibidos por miembros de partidos políticos y funcionarios del Gobierno del estado, pero sobre todo contar ahora con una base política que sirve de respaldo para las diferentes acciones.

Los discursos fueron analizados desde el análisis crítico del discurso al tratarse de elocuciones que provienen desde una posición privilegiada, pues las palabras emitidas desde estos movimientos sociales han impactado en una parte de la población y han tenido como intención el convencimiento de las masas de su forma de ver la realidad, búsqueda de soluciones entendiendo a la política como la actividad de incidir en las decisiones que afectan a la sociedad.

Los elementos analizados fueron emitidos por los mismos jóvenes en épocas diferentes, aunque no con una gran distancia en años (ya que se analizan discursos del YoSoy 132 en el periodo 2012-2014 y de Asamblea Popular Zacatecas en el periodo 2016-2017). En estos discursos se puede observar un cambio de temas y sobre todo de paradigmas, aunque una continuidad que lleva a la transición de una toma de conciencia que puede denominarse democracia deliberativa. En ese sentido, en el discurso de APZ se habla de "aprendizaje" como elemento clave que permitió el cambio de enfoque respecto a los discursos de 132 Zac de focalización maniqueísta donde los políticos son los malos y los jóvenes los buenos. La APZ persiguió una conciencia autocrítica y colectiva, que ya no pone a nadie en el banquillo de los acusados. En lo referente a los temas de los discursos, se hizo el siguiente cuadro comparativo que ilustra el cambio de ideología o bases de origen inherentes en los discursos. 


\section{Tabla 5}

Comparativo en temas de los discursos

\begin{tabular}{|c|c|c|}
\hline Tema & YoSoy 132 Zacatecas & Asamblea Popular Zacatecas \\
\hline Información & $\begin{array}{l}\text { Los medios mal informan o } \\
\text { desinforman. } \\
\text { Medios como aliados del } \\
\text { poder. }\end{array}$ & $\begin{array}{l}\text { Entender la capacidad } \\
\text { que se tiene de informar, } \\
\text { emplear las nuevas } \\
\text { tecnologías, ser capaz de } \\
\text { compartir información } \\
\text { verídica. } \\
\text { Ser el medio. }\end{array}$ \\
\hline Democracia & $\begin{array}{l}\text { Información como elemento } \\
\text { clave en la política para } \\
\text { emitir un voto razonado. } \\
\text { Voto informado para entrar } \\
\text { en la política. }\end{array}$ & $\begin{array}{l}\text { No esperar todo del Estado. } \\
\text { Participación social en la } \\
\text { política y/o rompimiento con } \\
\text { el Estado. }\end{array}$ \\
\hline $\begin{array}{l}\text { Sociedad } \\
\text { civil }\end{array}$ & $\begin{array}{l}\text { Exigir resultados a los } \\
\text { políticos, y elegir políticos } \\
\text { que puedan dar resultados. } \\
\text { Rendición de cuentas. }\end{array}$ & $\begin{array}{l}\text { Trabajar para obtener } \\
\text { resultados. } \\
\text { Ser parte de los resultados. }\end{array}$ \\
\hline
\end{tabular}

Fuente: elaboración propia a partir del corpus.

En el cuadro queda ilustrado el cambio ideológico en el discurso; el elemento más importante está en el paso de la rendición de cuentas a tomar la responsabilidad del cambio ellos mismos. En resumen, se trata de pasar de exigir la participación en otras esferas de la vida política, lo que implica la disminución de movilizaciones, marchas y protestas con el paulatino incremento de eventos artísticos, académicos e informativos.

En el caso de APZ, que es la experiencia más cercana en tiempo, los discursos estudiados están llenos de alusiones al crecimiento en el contenido de los discursos, en el aprendizaje continuo a través de la lectura de los autores referenciados y de la historia sobre los movimientos sociales, pero sobre todo al ejercicio de toma de conciencia y autocrítica, como un camino personal detonante del cambio. 
El 132 Zac tenía un tono más contestatario que respondía a una forma tradicional de hacer política, que denunciaba abusos y la toma de decisiones de una élite a la que exigían cuentas generales. En esta etapa los discursos estaban llenos de nombres y adjetivos para estos nombres, de figuras políticas que debían haber tomado decisiones "correctas" y no lo habían hecho. La democracia, concebida como la acción de trabajar para que las decisiones fueran tomadas por todos, quedaba sin mención. La fórmula discursiva de 132 Zac podía resumirse así: "yo, como ciudadano, te elijo, y con esa elección te doy la obligación de tomar buenas decisiones en todos los asuntos que me pudieran afectar, y me alejo para dejarte hacer tu trabajo y sólo vuelvo para hacerte notar tus errores".

La inclusión en APZ de conceptos como "el buen vivir", la recuperación de los esfuerzos zapatista e indigenistas, son todas propuestas de integración no sólo como miembros de un país, sino miembros de un entorno que hay que respetar. Estas propuestas son eco de un proceso mundial de pensamiento que bien podría estar dirigido por el Estado, al vivirse una grave crisis en la procuración de seguridad social.

Lo que parece ser un triunfo ideológico y una verdadera toma de conciencia siempre puede ponerse en tela de juicio, pues no es gratuito que muchos discursos latinoamericanos incursionen en este sentido justo en tiempos de crisis. El buen vivir se trata de una visión que afirma que cada persona es responsable de ser su propio proveedor del bien personal y con esto del bien común; sin embargo, no queda muy definido el lugar de un Estado que históricamente había sido paternalista y de bienestar.

Al final, para este trabajo lo que importa son los discursos, de los que se desprende una ideología. Los resultados de esta investigación son para el caso de Zacatecas, donde se da en el discurso el tránsito de una democracia delegativa 
y procedimental a una democracia delegativa de la que hay indicios hacia el año 2015, puesto que el discurso salvífico y utopista fue sustituido por uno autocrítico y de responsabilidad social compartida. Con base en el análisis de actores y contextos se constata que los discursos fueron emitidos por las mismas personas que pasaron de un movimiento al otro, lo que permite corroborar el cambio ideológico. Otro elemento importante es la transformación de la base de los discursos que después se articularon con movimientos sociales a nivel latinoamericano. En ambos casos las redes de poder y de formulación política pueden dibujarse.

Las redes de poder tanto en Zacatecas como a nivel nacional, están mediadas por las relaciones de parentesco y la mayoría de los líderes de 132 Zac y APZ son hijos de políticos o universitarios. Estos movimientos no nacieron de relaciones estudiantiles, ni de un sentir popular o de una unión; su legitimidad está dada por la red ya establecida. Hay una toma de conciencia, pues el discurso cambia de lo contestatario a lo de ciudadano activo, pero sumando los elementos contextuales la conclusión es que no se vive una democracia deliberativa, sino más bien intentos de ésta. Es decir, el tránsito a la democracia se da sólo en el discurso, pues las prácticas culturales y las acciones de estos movimientos están en el paradigma anterior.

La aportación de los casos estudiados consiste en que marcan una nueva etapa de movilización juvenil, que trasciende la capital y representa una toma de conciencia, no sólo a nivel universitario sino a nivel juvenil. En ese sentido YoSoy 132 y APZ significan la integración de la juventud y la ciudadanía en un esfuerzo por ser parte de la toma de decisiones, ampliando las esferas de la participación social. $\varepsilon$ 
Acosta, Alberto. (20I3). El Buen Vivir: Sumak Kawsay, una Bibliografía oportunidad para imaginar otro mundo. Barcelona: Icaria. Aguayo, Sergio. (20I5). De Tlatelolco a Ayotzinapa. Las violencias del Estado. México: Ediciones Proceso.

Aguilar López, Jesús. (20I5). Identificación partidaria de jóvenes mexicanos en el proceso electoral de 2012 . Revista Mexicana de Ciencias Políticas y Sociales, año LX, núm. 223, enero-abril.

Alonso Sánchez,Jorge. (20I3). Cómo escapar de la cárcel de lo electoral: El movimiento YoSoyl32. Desacatos, núm. 42, mayo-agosto.

Álvarez Torres, Cheryl. (20I4). El desarrollo de capacidades democráticas: La construcción de un sistema deliberativo para la inclusión política juvenil en Baja California.Tesis de Maestría en Desarrollo Regional. México: El Colegio de la Frontera Norte, A. C.

- (20I5). El sistema deliberativo y el desarrollo de capacidades democráticas en jóvenes. Buenos Aires: CLACSO, Serie Documentos de Trabajo, Red de Posgrados, núm. 61 .

Bookchin, Murray, Liguri, Domenico, y Stowaser, Horst. (2004). La utopía es posible. Experiencias posibles. Colección Utopia Libertaria.

Castelán, Samuel. (20I2). Yo soy 132. México: Panorama Editorial.

Cepal. (2008). Juventud y cohesión social en Iberoamérica. Un modelo para armar. Buenos Aires.

Chilton, Paul. (2004). Analysing Political Discourse:Theory and Practice. Londres: Routledge.

Díaz Cepeda, Luis Rubén. (20I5). Yo soy I32:A networked social movement of Mexican youth. En: Nahide Konak, y Rasim Özgür Dönmez, Waves of Social Movement Mobilizations in the Twenty-First Century: Challenges to the Neo-LiberalWorld Order and Democracy. Lexington Books.

Dryzek, John. (2000). Deliberative democracy and beyond: Liberals, critics, contestations. Oxford: Oxford University Press. 
- (2004). Pragmatism and Democracy. Journal of Speculative Philosophy, I8(I).

—. (2009). Democratization as Deliberative Capacity Building. Comparative Political Studies, 42(I I), noviembre.

Eckstein, Susan. (200I). Poder y protesta popular. Movimientos sociales latinoamericanos. México: Siglo XXI Editores.

Encuesta Nacional sobre Cultura Política y Prácticas Ciudadanas (ENCUP). (20I2). Resultados de la Quinta Encuesta Nacional sobre Cultura Política y Prácticas Ciudadanas ENCUP 2012. Disponible en: http://www.encup.gob.mx/ work/models/encup/resource/69/1/images/resultados-quinta-encup-20I2.pdf [consultado el 9 de febrero de 20I7]. Ercan, Selen, y Dryzek, John. (2015a). The reach of deliberative democracy. Policy Studies, 36(3): 24I-248. http:// dx.doi.org/ I0.1080/0I442872.2015.1065969

—. (20I5b). Conclusion:The reach of deliberative democracy. Policy Studies, 36(3):359-36I. http://dx.doi.org/I 0 .1080/0 I 442872.20I5.106597।

Espíndola Ferrer, Fabiana. (2016). Jóvenes en movimientos: Experiencias y sentidos de las movilizaciones en la América Latina contemporánea. Buenos Aires: CLACSO.

Facultad de Derecho. (2016). Profesor John Dryzek aborda relación entre protesta social y deliberación pública. Conferencia presentada en la Universidad de Chile, el 30 de agosto de 2016. Disponible en: http://www.derecho. uchile.cl/noticias/ I25550/prof-dryzek-aborda-relacion-entre-protesta-y-deliberacion-publica [consultado el II de febrero de 2017].

Fairclough, Norman. (2003). El análisis crítico del discurso como método para la investigación en ciencias sociales. En: R. Wodak y M. Meuer (coords.), Métodos de análisis crítico del discurso (pp. 179-203). Barcelona: Gedisa.

—. (2005). PeripheralVision: Discourse analysis in organization studies. The case for critical realism. Organization Studies, 26(6). 
Figueroa, Carlos. (2004). Reseña de "Genealogía de la Bibliografía revuelta.Argentina:La sociedad en movimiento" de Raúl Zibechi. Bajo elVolcán, 4(8):219-226. Puebla: Benemérita Universidad Autónoma de Puebla.

Figueroa, Silvana. (2007). Economía, trabajo y educación en Zacatecas:Temas de interés actual. Zacatecas: Gobierno del estado de Zacatecas.

García Zamora, Rodolfo. (20I6). La migración en la agenda pública de México: 1975-2016. Ola Financiera, núm. 24, mayo-agosto. México: Universidad Nacional Autónoma de México.

Gómez Tagle, Silvia, Tejera Gaona, Héctor, y Aguilar López, Jesús. (20I3). Informe de la Encuesta La cultura política de los jóvenes en México para el Instituto Federal Electoral. México: El Colegio de México. https://culturadelalegalidad.org.mx/recursos/Contenidos/Estadsticas/documentos/La\%20cultura\%20politica\%20de\%20los\%20 jovenes\%20en\%20Mexico.pdf [consultado el 10 de febrero de 20I7].

Hernández Hernández,Alberto, y Campos-Delgado,Amalia E. (20I5). Actores, redes y desafios. Juventudes e infancias en América Latina. Tijuana: El Colegio de la Frontera Norte. Holloway, John. (2002). Cambiar el mundo sin tomar el poder. El significado de la revolución hoy. Pluto Press.

Laclau, Ernesto, y Mauffe, Chantal. ( 1987). Hegemonía y estrategia socialista. Hacia una radicalización de la democracia. Madrid: Siglo XXI Editores.

Martínez Vilchis, José. (2013). Juventud y política: Fortalecimiento de una democracia incluyente. Espacios Públicos, 16(38), septiembre-diciembre, pp. 9-21.

Monsiváis Carrillo,Alejandro. (20।4). La deliberación como mecanismo de control democrático: Precisiones analíticas y cuestiones emergentes. Revista Mexicana de Sociología, 76(3), julio-septiembre, pp. 47 I-499. Distrito 
Bibliografía
Federal, México: Universidad Nacional Autónoma de México.

Morfín-López, C. (20I2). La reciente movilización política de los jóvenes: Expresiones locales de una crisis mundial. Análisis Plural, primer semestre. Tlaquepaque, Jalisco: ITESO.

Mumby, Dennis K., y Clair, Robin P. (2007). El discurso en las organizaciones. En:Teun A. van Dijk, El discurso como interacción social. Barcelona: Gedisa Editorial.

Murillo, Jorge, y Vergara, Adrián. (2004). Una propuesta de análisis textual a partir de los postulados del análisis del discurso. Filología y Lingüística, $x x x(I)$.

Ortiz Marín, Ángel Manuel. (2016). La cultura política de la juventud en México según la ENCUP 2012. Condiciones para mejorar la democracia. Espacios Públicos, 19(45). México: Universidad Autónoma del Estado de México.

Osorio, Jaime. (2014). El Estado en el centro de la mundialización. La sociedad civil y el asunto del poder. México: Fondo de Cultura Económicaéxico.

Palacios,Ana Elda. (20I3). Yo soy I32:Desarrollo y permanencia. Perspectivas desde la zona metropolitana.

Pardo, Neyla Graciela. (20I2). Análisis crítico del discurso: Conceptualización y desarrollo. Cuadernos de Lingüística Hispánica, núm. 19, enero-junio.

Pardo, Neyla Graciela, y Forero, Nelson Camilo. (20I6). Introducción a los estudios del discurso multimodal. Universidad Nacional de Colombia.

Programa de las Naciones Unidas para el Desarrollo. (2004). La democracia en América Latina. Hacia una democracia de ciudadanos y ciudadanas (pp. 16, 38 y 43). Buenos Aires: Aguilar/Altea/Taurus/Alfaguara.

Raveli, Louis, y van Leeuwen, Theo. (2018). Modality in the digital age. Visual Communication, I7(3): 277-297. 
Reguillo, Rosana. (2002). El otro antropológico: Poder y Bibliografía representación en una contemporaneidad sobresaltada. Análisis, núm. 29, pp. 63-79.

- (2007). Formas de saber. Narrativas y poderes diferenciales en el paisaje neoliberal. En: Grimson,A., Cultura y neoliberalismo.

—_. (2008). Las múltiples fronteras de la violencia:Jóvenes latinoamericanos entre la precarización y el desencanto. Pensamiento Iberoamericano, núm. 3. Disponible en: http:// www.pensamientoiberoamericano.org/articulos/3/84/2/ las-m-Itiples-fronteras-de-la-violencia-j-venes-latinoamericanos-entre-la-precarizaci-n-y-el-desencanto.html -. (20I2). Culturas juveniles. Formas políticas del desencanto. México: Siglo XXI Editores.

Saravi, Gonzalo. (20I5).Juventudes fragmentadas. Socialización, clase y cultura en la construcción de la desigualdad. México: FLACSO México/CIESAS.

Soler, Alcira, y Padilla, Antonio. (2010). Voces y disidencias juveniles. Rebeldía, movilización y cultura en América Latina. México: Ediciones Mínimas/Juan Pablos Editor.

Valenzuela, José Manuel. (20I I). Jóvenes, violencia y proyecto nacional.Working paper para el proyecto Plan de Desarrollo para Zacatecas, UAZ.

- (Coord.) (2015). Juvenicidio.Ayotzinapa y la vida precaria en América Latina. Barcelona: NED Ediciones.

Van Dijk, Teun A. (2003). Knowledge in parliamentary debates. Journal of Language and Politics, $2(\mathrm{I})$.

_. (2008a). Discourse and Context.A sociocognitive approach. Cambridge: Cambridge University Press.

—. (2008b). Discourse and Power. Contributions to Critical Discourse Studies. Houndmills: Palgrave.

- (2010). Discurso, conocimiento, poder y política. Revista de Investigación Lingüistica, núm. 13, pp. 167-2I5.

Van Dijk,Teun A. (Comp.) (1999). El análisis crítico del discurso. Barcelona:Anthropos. 
Bibliografía - (2000). El discurso como interacción social. Barcelona: Gedisa Editorial.

Van Dijk, Teun A., y Kintsch,W. (1983). Strategies of discourse comprehension. Nueva York/Londres: Academic Press.

Zibechi, Raúl. (2003). Genealogía de la revuelta. Argentina la sociedad en movimiento. Ediciones del FZLN. 